Wichtiges Ziel, schon vor mehr als hundert Jahren in unserer allerersten Satzung formuliert, muss es bleiben, die Stellung der Mathematik im geistigen Leben unserer Gesellschaft zu heben. Ideen sind gefragt! Warum fordern wir nicht Bundesjugendspiele Mathematik? Für alle, wie die gleichnamigen Wettbewerbe im Sport? Nein, nicht als ,Einzelwettkampf Jeder-gegen-Jeden' und bloß nicht als ,zentrale Klassenarbeit'. Aber schöne, die Kreativität fordernde Teamprojekte jenseits des aktuellen Schulstoffs, mitten im Leben, mit Urkunden - Kinder lieben so etwas -, zeitgleich im ganzen Land, in jeder Klasse, wie

\section{Internet: The Editor's Choice}

„Eines der seltsamsten und schönsten Bücher des [19.] Jahrhundert" nannte es der Experte für Druckkunst und Typographie, Ruari McLean. Gemeint ist die von Oliver Byrne 1847 editierte Ausgabe der ersten sechs Bücher der Elemente von Euklid. Diese Ausgabe versucht die Beweise Euklids durch farbige Graphiken mit wenig Text und unter weitgehender Vermeidung von Beschriftungen und Bezeichnungen darzustellen. Über den didaktisch-methodischen Erfolg lässt sich sicherlich streiten, über die typographische Qualität kaum. Das Buch wurde auf der Weltausstellung von 1851 präsentiert, der Verleger William Pickering musste 1853 vermutlich wegen der hohen Herstellungskosten Konkurs anmelden. Exemplare dieser Preziose erzielen auf Auktionen hohe Preise, so etwa im November 1996 die stolze Summe von 3220 US\$. Auf Initiative von Bill Casselman an der University of British Columbia wurde das Buch wäre das? Vielleicht ist die Zeit jetzt reif für einige ,unmögliche Dinge', wie Lewis Carroll es ausdrückt.

„Alice laughed: 'There's no use trying,' she said; 'one can't believe impossible things.' 'I daresay you haven't had much practice,' said the Queen. 'When I was younger, I always did it for half an hour a day. Why, sometimes I've believed as many as six impossible things before breakfast."

Herzliche Grüße

Ihr Peter Gritzmann

fotografiert, digitalisiert und so jedem im Internet zugänglich gemacht: http://www.sunsite.ubc.ca/ DigitalMathArchive/Euclid/byrne.html

Zusätzlich zur Ausgabe von Byrne wird der Kommentar aus der von Sir Thomas Heath 1908 herausgegebenen englischen Übersetzung der 13 Bücher der Elemente durch Link auf das Perseus-Projekt (http:// perseus.mpiwg-berlin.mpg.de/) einbezogen. Dort findet man auch die von Heiberg 1883-1886 herausgegebene, noch heute maßgebliche Ausgabe des griechischen Originaltexts.

Auf der Übersetzung von Heath basiert eine weitere Internetausgabe der 13 Bücher der Elemente von David Joyce mit eigenen Kommentaren, in welcher sich sämtliche Zeichnungen als Java-Applet dynamisch bewegen lassen: http://aleph0.clarku.edu/ djoyce/java/elements/toc.html
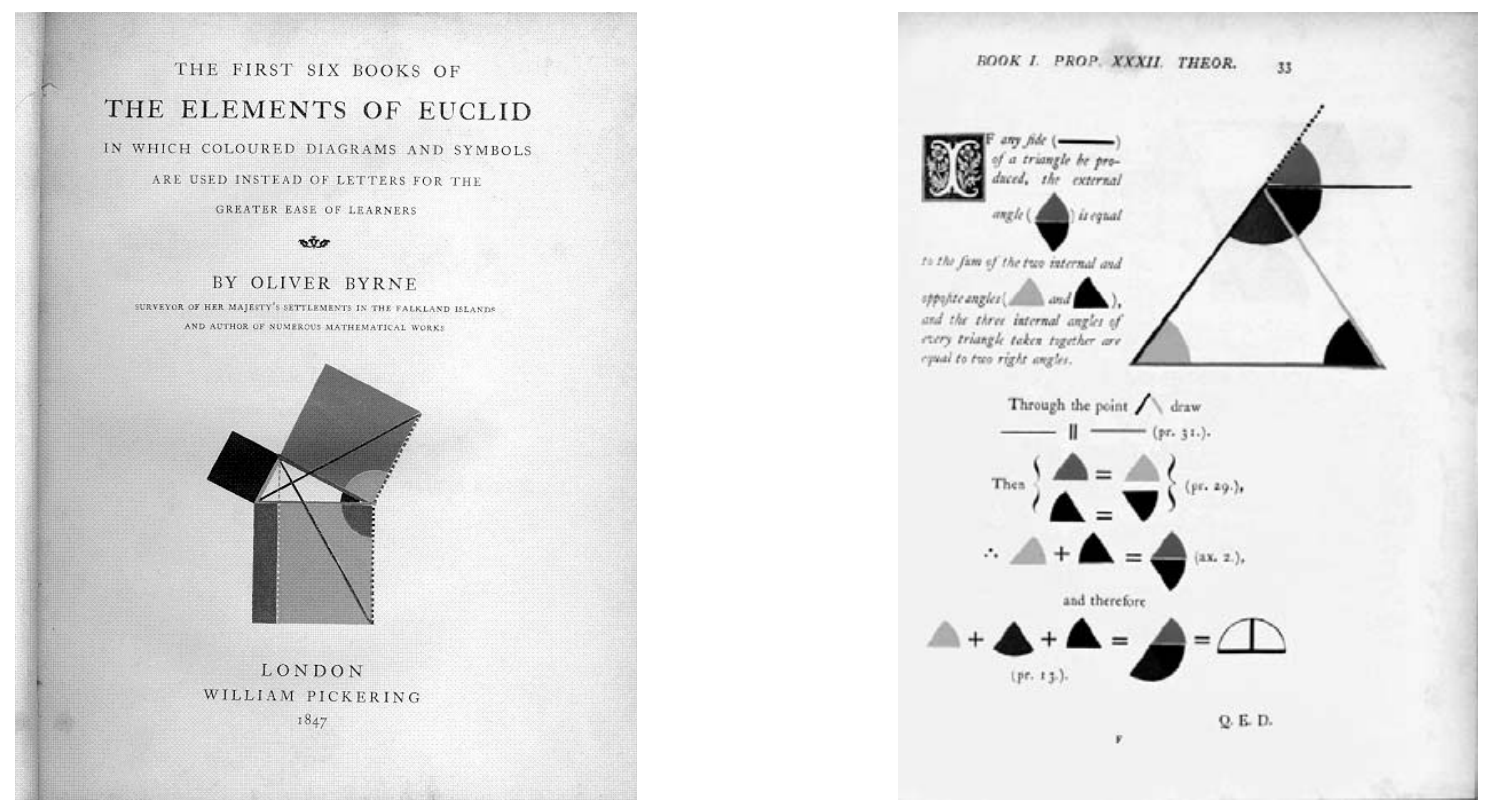